Talía. Revista de estudios teatrales

ISSN-e 2659-806X

\title{
Pedagogía e interculturalidad en el teatro infantil de Concha Méndez: El pez engañado
}

\author{
Beatriz Barrantes Martín*
}

Recibido: 16 de enero de 2020 / Aceptado: 30 de junio de 2020

Resumen: Concha Méndez fue partícipe del convulso mundo de la década de los años 30 del siglo XX; su interés por los contextos interculturales, así como su siempre infatigable afán pedagógico, son cuestiones cruciales que aparecerán en las obras que escriba durante ese tiempo. Este artículo se ocupa de analizar el acercamiento de Méndez al teatro desde una perspectiva integradora que intenta aunar esas dos vertientes (pedagogía e interculturalidad). Buen ejemplo de ello es la pieza titulada El pez engañado. En esta breve obra Concha Méndez consigue presentar una reveladora propuesta personal sobre su manera de entender la interculturalidad desde una perspectiva didáctica.

Palabras clave: Concha Méndez; teatro infantil; El pez engañado; pedagogía; interculturalidad.

\section{[en] Pedagogy and interculturality in Concha's Méndez children theatre: El pez engañado}

\begin{abstract}
Concha Méndez was a participant in the convulsive world of the 1930s; her interest in intercultural contexts, as well as her always indefatigable pedagogical zeal, are crucial questions that will appear in the works she writes during that time. This article analyses Méndez's approach to theatre from an integrative perspective that attempts to bring together these two aspects (pedagogy and interculturality). A good example of this is the play entitled El pez engañado. In this short play Méndez manages to present a revealing personal proposal about his way of understanding interculturality from a didactic perspective.
\end{abstract}

Key words: Concha Méndez; children theatre; El pez engañado; pedagogy; interculturality.

Cómo citar: Barrantes Martín, B. (2020). Pedagogía e interculturalidad en el teatro infantil de Concha Méndez: El pez engañado, en Talía. Revista de estudios teatrales, 2, 37-43.

Al hablar de Concha Méndez estamos refiriéndonos a una de esas mujeres que fueron representantes de toda una época generacional, social y cultural de la España de principios del siglo XX y el advenimiento de la República. Aquel grupo de mujeres simbolizaban ese espíritu rompedor y rebelde que se convertiría en el icono de la lucha por un hueco en el espacio cultural e ideológico que, en aquellos momentos, pertenecía en exclusividad al hombre ${ }^{1}$. Era el grupo que Concha Méndez, junto a su amiga Maruja Mallo, había comenzado a abanderar desde que un día salieran a las calles madrileñas sin sombrero y dieran lugar a lo que ahora conocemos como las "sinsombrero"2; entre ellas se encontraban mujeres dedicadas a todo tipo de actividad profesional, nombres de la talla de Marga Gil, María Teresa León, Josefina de la Torre, Rosa Chacel, Ernestina de Champourcín, María Zambrano y un largo etcétera. Eran, además, mujeres que habían pertenecido a los grupos intelectuales más selectos y que habían tenido lazos de amistad y camaradería con los principales integrantes de la Edad de Plata española. Federico García Lorca, Salvador Dalí o Luis Buñuel, por ejemplo, pertenecían al círculo frecuente de contactos de algunas de estas mujeres. Sin embargo, a menudo, su ausencia de la historia intelectual española

\footnotetext{
* Universidad Internacional de La Rioja

Email: beatriz.barrantes@unir.net

1 No hay que olvidar que estas mujeres coexistieron con aquellas otras que, al calor de la Revolución Industrial, también se incorporaron al mundo laboral en fábricas, talleres, etc. Estas tenían, obviamente, muchas menos oportunidades de progreso en sus condiciones por el hecho de ser mujer que las que se dedicaban a una actividad intelectual. Para este asunto, ver Barrantes Martín [2007: 74-75].

Para esta cuestión, véase el estudio de Tania Balló [2016].
} 
se debe, en parte, al propio olvido al que sus coetáneos varones las sometieron: no hay que olvidar que fue Gerardo Diego quien obvió cualquier nombre de mujer en su famosa antología Poesía española contemporánea de $1932^{3}$ (antología que determinaría la nómina "oficial" de la generación del 27) o que Luis Buñuel nunca presentó a sus colegas intelectuales a su compañera Concha Méndez 4 .

Dado el estado de la situación, estas mujeres tuvieron que asociarse para luchar por su proyecto feminista (recordemos, en este sentido, la importancia de la Residencia de Señoritas, el Lyceum Club femenino o la Asociación Universitaria Femenina). A este respecto, hay que señalar que Concha Méndez - como otras compañeras de generación- no se consideraba a sí misma feminista ${ }^{5}$, pero sí aparece a lo largo de su obra un elemento claramente reivindicador de la condición femenina, entendida esta no solo como una cuestión personal, sino desde una vertiente didáctica que permeaba a toda una generación de mujeres que se convirtieron, finalmente, en la bisagra que articuló el desarrollo de la modernidad española. De haber tenido éxito el intento republicano, estas mujeres habrían sido, sin duda, pilares fundamentales del cambio cultural, político, económico y social que se estaba generando en el entramado español de ese momento.

La literatura infantil de Concha Méndez continúa esa línea de la importancia de la función pedagógica que la mujer tiene en la sociedad que ya comenzó con mujeres como Carmen de Burgos (La mujer moderna y sus derechos), María de la O Lejárraga (La mujer moderna, Nuevas cartas a las mujeres) o Margarita Nelken (La condición social de la mujer en España). Es más, en consonancia con el legado de María de Maeztu, fundadora de la Residencia de Señoritas, así como en el marco del Lyceum $\mathrm{Club}^{6}$, en cuyas actividades Méndez participó activamente, la escritora también consideraba que la educación de la mujer, como transmisora del legado cultural a los niños, era fundamental. La mujer debía ser, por tanto, el motor del giro social hacia la alfabetización y el progreso cultural del país; y la labor debía empezar por la infancia.

Ese Lyceum fue un canal muy importante para la difusión del teatro de Concha Méndez ${ }^{7}$; en él publicó, por ejemplo, El carbón y la rosa. En su conferencia de 1942, "Historia de un teatro", Méndez recuerda que, en él, se hacía una intensa labor cultural y que, en una ocasión, para una fiesta de niños, le pidieron que teatralizase algún cuento de Andersen, para lo cual escribió El ángel cartero [Méndez 2001a: 71].

Para Concha Méndez, el didactismo era uno de los pilares fundamentales de su actividad literaria e intelectual. Toda su obra, desde su poesía a su teatro, pasando por su trabajo en la imprenta ${ }^{8}$, estaba enfocada hacia una visión "docente", totalmente visionaria para la época, donde entendía el papel del intelectual como el de un maestro que tiene la obligación de educar a una sociedad futura. Y este futuro pasaba por la educación de los niños. Concha Méndez se circunscribe a toda una corriente que se apoya en esta misma idea de que la literatura -la cultura, en su más amplia acepción- será el vehículo generador de una nueva España. El número de iniciativas al respecto fue muy reseñable, tanto en lo que se refiere a la producción artística (recordemos, por citar solo uno, el proyecto teatral de la Barraca que difundía el teatro clásico por los pueblos españoles y donde las mujeres cumplieron un papel fundamental), como a la intelectual. Como ensayo ejemplificador se puede mencionar Por la escuela renovada (1931) -en consonancia con el enfoque de Concha Méndez-, donde Carmen Conde, una de las principales promotoras del teatro infantil del siglo XX, señala la importancia de enseñar poesía a los niños $\mathrm{y}$, por tanto, de preparar a los maestros en el desarrollo de esa sensibilidad, una sensibilidad poético-cultural que sería la que Concha Méndez intenta establecer como centro de su proyecto teatral didáctico.

En este sentido, hay que destacar que ya hubo a principios del siglo XX una clara corriente relacionada con un teatro pedagógico escolar, pero este estaba enfocado, sobre todo, a la educación moral y religiosa; a dicho movimiento se adscribían nombres como Pilar Contreras, Micaela de Peñaranda, Matilde Ribot o Carolina Soto, pero, lógicamente, no caló en la producción teatral de Concha Méndez; por el contrario, ella siguió la vertiente de un teatro infantil más innovador del tipo del que cultivaron Magda Donato o Elena Fortún, como señala Nieva de la Paz [1993b].

El teatro infantil de Concha Méndez tuvo, no obstante, más dificultad que el de sus compañeras para verse difundido. Según Pilar Nieva, "tan sólo se ha localizado una representación de aficionados en el marco del Lyceum Club Femenino de su pieza infantil en un acto El ángel cartero" [1993a: 255]; esta representación tendría lugar el día de Reyes de 1929. Aunque quizá fuera también representada en Londres, como señala la propia autora en sus memorias: "Yo escribí El carbón y la rosa, una obra infantil escrita en Londres en los años 193435 , que es una obra de teatro para niños. En aquellos tiempos se había formado en Londres una compañía de teatro infantil que coincidía con la búsqueda de lo que yo había escrito" [95].

En esas valiosas memorias que la nieta de Concha Méndez publicó en 1990, se observa que la escritora ya muestra interés por el teatro en general desde temprana edad. A los trece años, tras asistir a una representación de Casa de muñecas, se muestra entusiasmada con el género dramático y comenta: "Cuando sea mayor -les dije a mis padres- escribiré teatro" [47].

Asimismo, en 1942, al recordar aquella actuación en su "Historia de un teatro", señalaba que "la idea de hacer

Hay que señalar que la reedición de 1934 incluye a las poetisas Ernestina de Champourcín y Josefina de la Torre.

Para estas actitudes machistas, ver los trabajos de Encarna Alonso [2016].

De hecho, Concha Méndez explica en sus memorias recogidas por su nieta Paloma Ulacia Altolaguirre, que no le gusta pertenecer a colectivos, que

ella se considera un individuo capaz de tomar decisiones autónomas no dirigidas por una conciencia global.

Para una descripción detallada del funcionamiento de esta institución, ver las memorias de Carmen Baroja y Nessi [1998].

Para una panorámica general del teatro infantil de Concha Méndez, ver Bados y Nieva de la Paz [2001].

Sobre el trabajo en la imprenta de Concha Méndez, ver Valender [2001b]. 
teatro la llevaba en la sangre, y todo mi ser se removió en aquel primer encuentro" [Méndez 2001a: 63]. De hecho, según la propia Méndez señala en el mismo escrito, para ella, "todo en la vida es teatro" [64].

El mismo entusiasmo demuestra cuando asiste al ballet ruso en Madrid en 1916, si bien hay que matizar que la propia Concha Méndez establece una clara jerarquía entre ambas artes. En "Historia de un teatro", de nuevo, la escritora opina que la danza puede ayudar a la acción teatral como elemento adicional, pero dado que no incluye palabra, es un arte prescindible, algo que no ocurre con el teatro:

La influencia del ballet cumplió en mí su cometido, pero había que pensar que la acción en el teatro no se basa en la música, sino en la palabra [...] El teatro, por lo demás, se afianza en la palabra. Y por medio de la palabra podemos llegar a una acción de fondo adonde la música nunca podrá realmente llevarnos. La expresión teatral tiene pues una fisonomía propia y de ella no se puede uno salir [Méndez 2001a: 66-67].

A pesar de que Concha Méndez es más conocida por su faceta de poetisa, el teatro fue también su gran motivación literaria. Por una parte, están los textos dramáticos que fue elaborando a lo largo de su vida: El ángel cartero (1931), El carbón y la rosa (1935), El pez engañado, Ha corrido una estrella y el "Prólogo" de El solitario ${ }^{9}$; por otra, su capacidad reflexiva y analítica sobre la práctica teatral, en general, y sobre su trayectoria como dramaturga, en particular, que se puede observar en los diferentes textos que escribió al respecto.

De hecho, es interesante rastrear, de forma cronológica, el recorrido metatextual de Méndez de su propia evolución teatral. A finales de los años veinte del siglo XX comienza a adentrarse en ese mundo y ya en 1927 se puede leer en un texto tomado de un recorte de periódico no identificado que Concha Méndez no solo tenía la idea de hacer teatro, sino que ya había comenzado a escribirlo. En esa entrevista, realizada durante el estío en su San Sebastián veraniego habitual, Méndez concreta más diciendo que incluso tiene "presentada para su lectura, a la compañía Díaz Artigas [...][su] primera producción, una comedia titulada El personaje presentido" [Valender 2001a: 25]. Un año después, en 1928, continúa en otra entrevista ${ }^{10}$ :

- Llevo publicados -dice- dos libros poemáticos. Ahora estoy haciendo teatro moderno.

- ¿A la manera del grupo Caracol?

- Menos íntimo que el de esa familia gasterópoda. De más eficiente universalidad. Mi intento ya tiene un título: Seres y sombras.

Su tarea de dramaturga no cesa cuando decide tomar rumbo a Argentina; muy al contrario, en 1929 considera que su viaje a Latinoamérica ayudará al despegue de su obra teatral: "Aunque parezca que el viaje que voy a empezar me desvía de mi orientación hacia el cinema y el teatro moderno, la realidad no es esa. En América pienso ver estrenada alguna obra mía, cosa que en España e Inglaterra sería difícil de lograr" "11 [Valender 2001a: 48].

Ya en Argentina, los escritos y entrevistas de Concha Méndez pasan de constatar su interés por el teatro a empezar a hacer un análisis más profundo de lo que significa este arte para ella desde un punto de vista artístico e ideológico. Se adentra incluso en la valoración del teatro de siglos anteriores. En un recorte sin fecha del periódico La literatura argentina, recogido en la misma compilación de Valender que venimos utilizando [2001a], Méndez reflexiona sobre el teatro de una manera que podría ser la introducción a toda una poética teatral:

El teatro necesita de una renovación, es decir, de una creación nueva; no para hacer un teatro en verso, que lo hicieron los clásicos [...], sino un teatro en prosa, lírica o no lírica, pero creada por la imaginación del poeta. Solo a la fuerza de ser poeta se puede llegar a la realización del gran drama [...], a la creación de grandes personajes. Teatro y cinema ofrecen un vastísimo campo de posibilidades y hasta me atrevería a decir que son dos fases del Arte que están en sus comienzos. ¿Es verdaderamente teatro lo que se nos ha dado con tal nombre en el transcurso de los siglos? Para mí no es sino literatura con pretensiones de espectáculo [52].

La cita anterior es breve, pero Concha Méndez plantea cuestiones muy relevantes sobre la situación teatral de su momento histórico, como la importancia de un teatro poético - no necesariamente lírico-que conectara el género con la imaginación del autor, la asimilación de teatro y cine como fases de un arte que necesita de una perspectiva radicalmente moderna (el teatro para renovarse y el cine para inventarse) o el cuestionamiento de cuáles son las características intrínsecas del género teatral que lo diferencian de una literatura simplemente "hablada".

A pesar de la capacidad intelectual y crítica de Méndez sobre el género teatral, sus comienzos en la operativa dramatúrgica como tal no fueron, sin embargo, fáciles. El hecho de que una mujer se independizara ya era sumamente complicado; más aún si esta mujer quería ser dramaturga. Méndez nos deja testimonios realmente relevantes al respecto. En su "Historia de un teatro" cuenta cómo, tras haber comentado con unos amigos que le interesaba el teatro, la invitaron a su casa a conocer a un ilustre actor español. La velada no pudo ser más desalentadora para el interés de Concha Méndez por dedicarse al teatro:

Hablamos, y el ánimo que este hombre me vino a dar fue el decirme que no perdiera lastimosamente mi tiempo, pues teatro en realidad lo habían intentado hacer miles y miles de personas y entre estos miles,

\footnotetext{
Que incluye una nota introductoria de María Zambrano.

10 Localizada en otro recorte de periódico no identificado [Valender 2001a: 34]

11 Texto recogido en el número de noviembre de 1929 de La Gaceta Literaria.
} 
apenas si en la historia del teatro habían quedado, a través de los siglos, dos docenas de hombres; además, yo era mujer y las mujeres nunca habían hecho teatro. Yo le argumenté que, si es cierto que nunca lo han hecho, eso no podía significar que alguna vez no pudieran hacerlo [Méndez 2001a: 64].

La reflexión de Concha Méndez sobre sus comienzos, interés y objetivos en el teatro en general se ven imbricados en la vertiente particular de su teatro infantil. Como bien observó Méndez en algunos de sus escritos, este tipo de dramaturgia gozaba de escasa tradición en España, a diferencia de lo que ocurría en otros países como Italia o, muy especialmente, Inglaterra. Allí, señala Méndez, se representaban multitud de obras teatrales infantiles que disfrutaban tanto niños como padres:

Allí pude ver representar el famoso Peter Pan de Lord Barrie y el no menos famoso Pájaro azul de Maeterlinck. Y eché de menos en la tradición de nuestro grandioso teatro español las obras de este tipo. ¿Por qué nosotros no nos habíamos ocupado nunca de mirar hacia esa maravilla que es la infancia? Y sin embargo ¡qué vastísimo campo ofrecía, qué perspectivas de actuación! [Méndez 2001a: 71-72].

La propia Concha Méndez comenta en una conferencia inédita titulada "Un teatro para niños" que, al ver el teatro infantil que se publica y representa en Londres y la inexistencia del mismo en España, decide:

Escribir un teatro de ese tipo para ese pequeño público que no deja de ser el gran público puesto que se trata de seres del porvenir y, esto es lo más interesante, formar las almas del futuro, despertando en ellas lo mejor que llevan en sí, inculcándoles por la vía poética una verdadera moral. Este es, a mi entender, el sentido de todo teatro infantil [Méndez 2001b: 2].

Esta cita incluye, como se puede ver, tanto un mensaje de necesidad de un teatro infantil en España, como un elemento claramente pedagógico donde se lleva a cabo el requerimiento de que ese teatro forme al niño del futuro de que hablábamos más arriba. De hecho, Concha Méndez señala en la entrevista de 1927 mencionada anteriormente que piensa dedicarse a dos formas de teatro, el "corriente", de intención moralizadora, y el "moderno"12, de carácter puramente artístico. Es interesante esta afirmación de Concha Méndez porque, aunque señale esa división de forma teórica, la complejidad de su pensamiento y su teatro no encajaban bien en moldes tan rígidos. De hecho, aunque esa clasificación responde a su admiración tanto por el teatro simbólico de Maeterlinck como por el didáctico que quiere poner en marcha, la realidad es que el teatro de Concha Méndez aúna ambas características, algo que le confiere un mayor valor artístico y conceptual.
Prosiguiendo con el asunto del didactismo en Concha Méndez y su sed de aprendizaje para sí misma y para otros que mencionamos al comienzo de este trabajo, encontramos su pasión por los viajes, que la llevará a diferentes localizaciones, ya sea por inquietud personal o por su finalmente forzado exilio. Esa necesidad de amplitud de horizontes se relaciona claramente con la vertiente pedagógica de la apertura a otras personas, razas y culturas, elemento fundamental en varias de sus obras teatrales infantiles, como veremos más adelante. En este sentido, el perspectivismo ideológico de Concha Méndez entrelaza, a un tiempo, su manera de entender la vida -ampliar horizontes para poder entender al otrocon su literatura. El ángulo de visión será el elemento central para la comprensión del prójimo, pero lo será también para llegar a la completa comprehensión creadora:

El teatro es un poco como el ojo de una cerradura por la que se asomará el espectador a ver lo que pasa en la intimidad de un ser [...] Se habla de realismo, de surrealismo. ¿Qué más da? [...] Es cuestión de enfoque $[. .$.$] Las cosas se pueden ver de tan diferen-$ tes ángulos, que de un mismo hecho pueden sacarse infinitas consecuencias: todo depende de un cierto ángulo visual y esto es lo que más en cuenta ha de tener todo creador [Méndez 2001a: 67].

Desde pequeña la escritora manifiesta una gran avidez por aprender y descubrir nuevos mundos, pero muy pronto este anhelo es aplacado por sus padres, quienes le prohíben continuar los estudios una vez terminados los más elementales y la confieren a las limitaciones del mundo destinado a toda mujer en la España católica y tradicional de aquel momento. Es por ello por lo que, enseguida, el viaje se revela como una forma de alcanzar ese primer deseo; así lo expresa la misma Méndez cuando recuerda: "El viaje era un deseo que nació en mi infancia cuando miré desde mi pupitre los mapas suspendidos en el muro del colegio. Viajar era viajar, pero era también liberarme de mi medio ambiente, que no me dejaba crear un mundo propio, propicio para la poesía" [Ulacia y Méndez 1990: 83].

Ante tales circunstancias, el viaje se presenta como una liberación del ambiente opresivo en el que vive, pero también supone un exilio, primero interior, más tarde exterior. De hecho, Concha Méndez se considera "ciudadana del mundo porque quiero hacer de él como una gran vivienda, en la que cada país sea una estancia distinta por las que quiero ir pasando hasta recorrerlas todas"13 [Méndez 2001a: 52].

Antes de la República, viaja, en 1929, a Inglaterra, Uruguay y Argentina y, tras volver a España, conoce a su futuro marido, Manuel Altolaguirre, con quien volverá de nuevo a Londres, donde residirán de 1933 a 1935. El matrimonio y su hija regresan a España en 1935 y, al estallar la Guerra Civil, ambos toman partido por la República, pero Concha Méndez y su hija se ven forzadas a abandonar Madrid, mientras Altolaguirre permanece

\footnotetext{
"Corriente" y "moderno" son los términos literales que usa Concha Méndez en dicha entrevista.

13 Aparecido en La Literatura Argentina, p. 246 (recorte sin fecha).
} 
en España. Tras residir en Inglaterra, Bélgica y Francia, regresa a Barcelona para reunirse con su marido, camino ya del exilio. Se trasladan a París y más tarde a La Habana, donde permanecen hasta 1943, y coinciden con otros muchos exiliados. En 1944, se trasladan a México. Concha Méndez nunca regresa a España, salvo un viaje a Madrid en 1966, tras el cual vuelve a residir en México hasta su fallecimiento en 1986.

En cualquier caso, los viajes de Concha Méndez, sobre todo los iniciáticos de finales de los años veinte $\mathrm{y}$ principios de los treinta, fueron fundamentales para forjar su personalidad tanto humana como artística y le permitió ampliar horizontes y valorar al otro en toda su extensión y complejidad multicultural:

El trasplantarse a un ambiente totalmente distinto amplía proyectos e ideas. Es como un sondeo en los espacios desconocidos, o más bien presentidos. En la reacción ante las cosas y los hechos se tropieza con verdaderos hallazgos. En Londres era yo como un triple receptor de emociones y sensaciones. Todo nuevo ante mí. Mientras, mis bolsillos vacíos. Y la vida de frente, mirándome fija y desconcertante. Por mí, un desfile de cifras y kilómetros y más proyectos. Fue el despertar a mi realidad: Libertad. Lucha verdadera $^{14}$ [Valender 2001b: 45].

El interés pedagógico de Méndez, así como los temas del viaje y la interculturalidad, aparecen de forma significativa en El pez engañado, obra que sigue la tradición del relato bíblico de Jonás en el vientre o el famoso episodio de Las aventuras de Pinocho. De hecho, para Concha Méndez, la fantasía es el elemento fundamental y vertebrador del descubrimiento de la realidad. En su "Historia del teatro" así lo expone:

Cuando yo elegí para mi teatro los caminos de la fantasía y del simbolismo [...], no conocía esta frase de Goethe ["La fantasía está mucho más cerca de la Naturaleza que la sensualidad; esta está contenida en la Naturaleza, aquella se cierne encima de ella"], pero tal vez me conocía a mí misma y subconscientemente pensé que por esos dos caminos podía marchar: de acuerdo con mi propia naturaleza y con la Naturaleza misma, por encima de ella. El campo de la fantasía tiene, por lo demás, una realidad mucho más sorprendente. En ella podemos aunar la gracia del misterio y sacar a la luz de vida cuantas pasiones se puedan dar en la variedad del ser. La fantasía no idealiza, ni deforma, ni limita los seres y las cosas; tampoco es la desviación de los mismos. La fantasía penetra, descubre, recrea y amplía la esencia de todo ser y nos lo hace ver con el lujo de lo ilimitado [Méndez 2001a: 76].

El pez engañado comienza narrando una tranquila tarde donde unos niños están observando una regata marinera. En la siguiente escena se nos muestra ya el interior de la ballena convertida en un acogedor habitá- culo donde hay todo tipo de muebles y enseres: camas, muebles, platos.

El tema central pivota en torno a un gran pez, una ballena, que, poco a poco, se va tragando a diferentes personajes, entre ellos un hombre mayor y varios niños de diferentes orígenes étnicos. Debido a la imposibilidad de salir del monstruo, estos personajes construyen su vida allí e irán articulando una interesante dinámica social y dramática que dará lugar a diferentes situaciones hasta que, finalmente, idean una solución para poder liberarse.

El didactismo del que hemos hablado más arriba, casi siempre presente en las obras de Concha Méndez, determina aquí el desarrollo del argumento dramático, esta vez en forma de interculturalidad, entendida esta como el concepto que se centra en el intercambio de gentes, ideas y normas culturales y en el desarrollo de relaciones profundas. Méndez, desde su reseñable apertura mental, entiende que, en toda sociedad, debe existir un profundo entendimiento y respeto por todas las culturas; en una sociedad intercultural, nadie se queda sin intercambio porque todos aprenden de los demás y crecen juntos.

El pez engañado es, de esta forma, un proyecto adelantado a su tiempo que cobra en la actualidad una sorprendente contemporaneidad. Los personajes de los niños en esta obra son un oriental, un negrito ${ }^{15}$, un esquimal, un indio, un árabe y una niña europea. Los seis, a lo largo de su periplo en el estómago del pez, van contando historias sobre sus orígenes, sus costumbres o sus países, con lo que el mensaje que se transmite a un potencial público infantil es sumamente enriquecedor.

El primer diálogo incluye ya un incipiente relato intercultural. El niño árabe y el oriental están hablando sobre el largo sueño de la niña y señalan:

Árabe: Lleva ya no sé cuántas horas durmiendo.

Oriental: ¡Falta le hacía descansar! ¡Pobrecilla! Cuando llegó creí que del ataque no salía...

Árabe: Tiene unos nervios...

Oriental: Es que el susto debió de ser muy grande. Acuérdate de cuando llegaste tú, y eso que tú eres de una raza muy tranquila.

Árabe: La verdad es que faltaba un europeo y aquí la tenemos. Somos ya uno de cada raza. [74]

Es interesante reseñar aquí los estereotipos que Concha Méndez recoge, y tampoco es baladí el hecho de que el único europeo pertenezca al género femenino.

Más adelante los niños van describiendo sus países y costumbres. El niño oriental señala que en su país "tenía un jardín y en el jardín muchas flores. Y tenía kimonos bordados... Durante mucho tiempo yo no salía de aquel jardín. En él me enseñaron a leer y aprendí a contar y a escribir" [77].

De igual forma, el niño negrito señala que él vivía "en una choza cerca de la marina" y que tenía "una piragua hecha con la madera más fina y tan ligera que cualquier niño podía manejarla" [78].

\footnotetext{
14 Cita de "Los raids literarios. Conversación con Concha Méndez”, La Gaceta Literaria, 69, Madrid, 1 noviembre $1929,3$.

15 Se utilizan en este artículo los términos literales que Concha Méndez acuña en su obra; en este caso "negrito".
} 
Todos los niños tienen interés en conocer las vidas de los demás (recordemos esa sed de Concha Méndez por abrir horizontes y conocer otras culturas y otros mundos). En un momento dado, los niños se interesan por la vida del niño esquimal, que explica las costumbres de su familia:

Nos abrigábamos con la piel de los animales. Teníamos trineos que corrían sobre la nieve tirados por enormes perros. Así íbamos de viaje por la estepa. Eran días de frío... se helaba hasta el aliento. Cuando se fatigaban de correr los perros, hacíamos alto en el camino. Con bloques de nieve helada cortados a cuchillo, construíamos un albergue con una entrada muy pequeña [80].

Más allá del didactismo sobre el interés intercultural, es interesante apuntar que la obra alcanza un nivel superior al incluir el concepto de proyecto cooperativo entre los miembros de todas esas razas. Es decir, Concha Méndez no solo defendía el respeto a los valores culturales de individuos de países distantes, sino que se percataba del potencial y la fuerza que podía tener la unión de los diferentes rasgos diferenciadores de cada uno de esos grupos raciales. Al niño oriental se le ocurre la idea de abrir seis ventanas en los laterales de la ballena y utilizar las costillas de la ballena a modo de remos. Además, con los mapas y la brújula que tiene en su maletín se orientarán para llegar a puerto. Todos aplauden la propuesta y se disponen a llevarla a cabo. Finalmente llegan a una ciudad europea y la niña se muestra feliz por llegar a tierra conocida. Pero los demás, abiertos siempre de mente, también se congratulan por la posibilidad de ver lugares nuevos. El niño negrito, por ejemplo, exclama que él es africano, pero que desea ver Europa "donde dicen que todo es maravilloso, las casas, los trenes, las calles, los escaparates, las luces...! ${ }^{16}$ [103]. También el niño esquimal, por su parte, se alegra de ver un lugar donde no solo hace frío.

$\mathrm{Y}$, en medio de todo este alarde de respeto intercultural, se cruza también la tolerancia hacia el género femenino, otro de los temas didácticos tan presentes en Concha Méndez y que mencionamos al comienzo de este artículo. En un principio, todos los niños que ha tragado la ballena son varones, pero, en un momento dado, hace su aparición dentro del pez la niña. El niño oriental comenta: “¿No estáis contentos con que sea una niña?" [76], a lo que el niño árabe contesta: "Claro que es mejor. Todos éramos niños antes de que ella viniera" [76].

Es más, este feminismo cobra un giro realmente interesante cuando la igualdad de la mujer se presenta como un rasgo totalmente contemporáneo, ya que no aparece un feminismo distinguidor desde un punto de vista positivo, sino que la mujer debe acatar las consecuencias de su equiparación y funcionar en la sociedad en igualdad de condiciones. En la representación de esta cuestión en El pez engañado aparece perfectamente retratado el papel que Concha Méndez cumplió en su vida, cuando trabajaba como cualquier hombre en su imprenta vestida con mono y manchándose las manos de tinta.

Dicho asunto aparece representado en esta obra teatral de forma contundente. Cuando los personajes intentan escapar del pez, en un momento dado, el niño árabe se pregunta: “¿Dejamos dormir a la niña?”, a lo que el viejo responde: "Debe remar como todos" [94].

Este artículo se ha centrado en la obra de El pez engañado, pero el tema pedagógico de la interculturalidad y la tolerancia hacia otras razas y personas aparece también en otras obras infantiles de Concha como, por ejemplo, El carbón y la rosa, pieza escrita en Londres, dedicada a la hija del matrimonio Méndez-Altolaguirre, Paloma, y estructurada en tres actos con un epílogo final.

El carbón y la rosa narra la historia de amor entre el Carbón, un negrito ${ }^{17}$ adolescente y la Rosa, una muchacha vestida de ese color. En un principio, la Rosa es arrogante y altiva y no quiere considerar el amor de alguien de raza negra. Ante el desprecio de la Rosa, el Carbón protesta:

CARBÓN: ¿Me desprecias porque es oscuro mi color? Algunos blancos tratan mal a los negros, injustamente. Pero debieras saber que mi amor es rubio como el fuego y que mi corazón es un brillante blanco, blanco purísimo $[\ldots]$

¿Por qué pedirte que me quieras? Sé que es demasiado.

ROSA (ofendida): ¿Pedirme demasiado?

CARBÓN: Pedirte un imposible.

ROSA (colérica): ¿Crees que no soy capaz de querer? Pues que sepas que soy capaz y muy capaz, pero a un mamarracho como tú que tizna y es más negro que una noche sin luna, no.

CARBÓN: Aprenderé a bailar y cantar si tú quieres. ROSA: Tus canciones serán negras como tu voz [13$16]$.

La obra continúa con el Carbón intentando conseguir el amor de la Rosa y, para ello, habla con un Duende que le recomienda raptarla, llevarla a su palacio y enamorarla con sus virtudes hasta que la Rosa llegue a admirarle y quererle.

Pero el Carbón sigue desesperado y quejándose del racismo de la Rosa: "Yo le daba cuanto calor podía y, sin embargo, me aborrecía [...] Y es que yo soy de raza oscura, y eso, algunos blancos no lo perdonan. ¡Es injusto, es injusto!" [56].

Concha Méndez plantea de forma muy eficiente un tema totalmente contemporáneo que, dado el carácter infantil de esta obra, se resuelve, como no podía ser de otra forma, en un final feliz: la Rosa se da cuenta del buen corazón del Carbón (que, en realidad, es un diamante blanquísimo) y le entrega su amistad.

Como hemos podido observar en este trabajo, la figura de Concha Méndez presenta una proyección más allá de la importancia que se le dio en un momento inicial. Fue poetisa, narradora, editora, dramaturga y, en lo que se refiere a esta última faceta, Méndez destaca 
por incluir en su teatro infantil diferentes y variados elementos que hacen de su producción dramática un importante legado. Al llevar a cabo el análisis concreto de El pez engañado, se ha podido observar la significación de diferentes aspectos distintivos, esto es, el didactismo y la interculturalidad. Concha Méndez escribió su producción teatral infantil pensando en educar a toda una generación futura de niños. Todas estas obras destacan por un componente pedagógico que varía te- máticamente entre ellas. En el caso de El pez engaña$d o$, Méndez opta por la cuestión de la interculturalidad; son, además, los propios niños el cauce elegido para presentar la importancia de la comprensión interracial, el respeto al otro y el intercambio colaborativo. Con esta pieza teatral, Méndez pretendía educar a una sociedad que, como bien supo ella misma ver, se iba a caracterizar por la generosidad y la empatía hacia lo diferente.

\section{Referencias bibliográficas}

Alonso Valero, Encarna (2016): Machismo y vanguardia. Escritoras y artistas en la España de Preguerra. Madrid, Devenir.

Bados Ciria, Concepción (2009): "Intelectuales de la Edad de Plata. Concha Méndez y el teatro infantil”, Centro Virtual Cervantes, Recurso web $<$ http://cvc.cervantes.es/el_rinconete/anteriores/mayo_09/27052009_02.htm $>$, Fecha de consulta: 20 -II-20.

Balló, Tania (2016): Las Sinsombrero, Madrid, Espasa.

Baroja y Nessi, Carmen (1998): Recuerdos de una mujer de la generación del 98, Madrid, Tusquets.

Barrantes Martín, Beatriz (2007): “Apropiándose el espacio urbano: mujer y ensayo en la construcción de la modernidad española”, Ciudad y modernidad en la prosa hispánica vanguardista, Valladolid, Servicio de publicaciones de la Universidad de Valladolid: 73-98.

Conde, Carmen (1978): Por la escuela renovada, Murcia, Servicio de publicaciones de la Universidad de Murcia.

García Jaramillo, Jairo (2013): La mitad ignorada. (En torno a las mujeres intelectuales de la Segunda República), Madrid, Devenir.

Méndez, Concha (1931): El personaje presentido. El ángel cartero, Madrid, Imprenta de Galo Sáez.

- (1998): El solitario, Madrid, Universidad de Alcalá.

- (2001a): "Historia de un Teatro", en James Valender (ed.), Una mujer moderna. Concha Méndez en su mundo (1889-1886), Madrid: Publicaciones de la Residencia de Estudiantes: 63-77.

- (2001b): "Un teatro para niños", en James Valender (ed.), Una mujer moderna. Concha Méndez en su mundo (1889-1886), Madrid: Publicaciones de la Residencia de Estudiantes: 2-8.

- (2003): El carbón y la rosa, Madrid, Caballo griego para la poesía.

- (2006): El pez engañado. Ha corrido una estrella. Las barandillas del cielo, Madrid, Asociación de Directores de escena de España.

Nieva de la Paz, Pilar (1993a): Autoras dramáticas españolas entre 1918 y 1934, Madrid, CSIC.

- (1993b). "Las escritoras españolas y el teatro infantil de preguerra. Magda Donato, Elena Fortún y Concha Méndez", Revista de Literatura, Madrid, CSIC, vol. LV: 112-128.

- (2001). "El teatro infantil de Concha Méndez", en Valender, J. (ed.), Una mujer moderna. Concha Méndez Cuesta en su mundo (1898-1986), Madrid, Publicaciones de la Residencia de Estudiantes.

Ulacia Altolaguirre, Paloma (1990): Concha Méndez. Memorias habladas, memorias armadas, Madrid, Mondadori.

Valender, J., ed. (2001a): Una mujer moderna. Concha Méndez Cuesta en su mundo (1898-1986), Madrid, Publicaciones de la Residencia de Estudiantes.

- (2001b): Manuel Altolaguirre y Concha Méndez. Poetas e impresores. Madrid, Publicaciones de la Residencia de Estudiantes. 